\title{
The psychosocial needs of leprosy patients
}

\author{
J. SCOTT \\ PO Box 1562, Kroonstad, Free State 9500, South Africa
}

In the world of today one finds that between 11 and 12 million people have suffered from leprosy. ${ }^{1}$ Much research has been conducted on the medical aspects of leprosy, but there is a need in various parts of the world for specialized studies of the psychosocial aspects of leprosy. ${ }^{2}$ This need relates to the fact that comparatively little research on the psychosocial needs of leprosy patients has been done. In South Africa, a total of 10,812 patients were registered in $1984 .{ }^{1}$ It cannot be assumed that patients in South Africa will manifest the same psychosocial needs as leprosy patients in other parts of the world. Judged by research done mainly in other parts of the world, it can be inferred that the psychosocial needs of leprosy patients are dissimilar. Their needs appear to be three-fold: the need for self, societal and community acceptance. Self-stigmatization after diagnosis is not only true of leprosy sufferers, ${ }^{3}$ and is often of a permanent nature. ${ }^{4}$ Some leprosy sufferers never accept the disease. $^{5}$ A specific need of self-acceptance is required in a sufferer. Many patients are rejected by their families on account of the latter's fear of leprosy. They may even request the patient to leave home. ${ }^{6}$ According to Van Parijs, ${ }^{7}$ one-third of leprosy patients suffer desertion by marriage partners. When a divorce follows after a diagnosis of leprosy, the emotional consequence are even more devastating. Often, leprosy sufferers are treated very unsympathetically. ${ }^{8}$ Leprosy has become symbolic of highly stigmatized and feared circumstances. The rejection of leprosy patients is illustrated by the fact that many lose their work. At the root of the act of rejection lies an employer's fear that the leprosy sufferer may transmit the disease. Leprosy patients may not be sympathetically treated in medical instances; in India, cases have been reported of doctors refusing to treat leprosy patients. ${ }^{9,10}$ Leprosy sufferers have a strong desire to be accepted in the community, especially in the labour market.

There is limited understanding of the psychological needs of leprosy sufferers in South Africa. The purpose of this study is to answer the following questions:

- What is the nature and intensity of the emotional perceptions of the diagnosis of the disease by leprosy sufferers?

- Why do some leprosy patients consult a Sangoma (traditional healer) before consulting a medical doctor?

- Are leprosy sufferers generally satisfied with medical treatment that they receive?

- Is the divorce rate in leprosy sufferers in Southern Africa as high as the rest of the world?

Correspondence to: J. Scott (e-mail: James@qedi.co.za) 
- How does leprosy affect the family life of the leprosy sufferer?

- Is there any discrimination against leprosy sufferers in the labour market?

\section{Materials and methods}

SUBJECTS

The study group $(n=30)$ consisted of 15 black male and 15 black female patients between the ages of 41 and 60 years, selected at random from the leprosy population. The ethnic derivation of the sample is shown in Table 1.

\section{STUDY DESIGN}

This study used semi-structured interviews with the aid of an interview schedule with respondents.

\section{PROCEDURE}

Biographical information that included medical and psychosocial history was collected from each respondent. Questions concerning the interview schedule were formulated in the respondent's own idiom. Psychosocial needs identified in the literature served as background for the compilation of open as well as closed questions. Questions were asked about the emotional experience, the influence that leprosy had on their married and family life, their subjective perception of hospitalization and how they experienced community rejection. The interviews were restricted to $1 \mathrm{~h}$. The interviewer was a Master's student in Counselling Psychology; a woman who had command of four regional languages in addition to Afrikaans and English served as interpreter. The interviews were conducted at two locations. Interviews were held with 21 institutionalized patients at Westfort Hospital and nine subjects were interviewed in their own environment.

\section{Results}

RESPONSE TO DIAGNOSIS OF LEPROSY

During the interview, the respondents had to explain the nature and intensity of a variety of

Table 1. Ethnic derivation of respondents

\begin{tabular}{ll} 
Ethnic derivation & $n$ \\
\hline Sotho & 7 \\
Swazi & 7 \\
Zulu & 6 \\
Ndebele & 3 \\
Tswana & 3 \\
Xhosa & 2 \\
Shangan & 2 \\
\hline
\end{tabular}




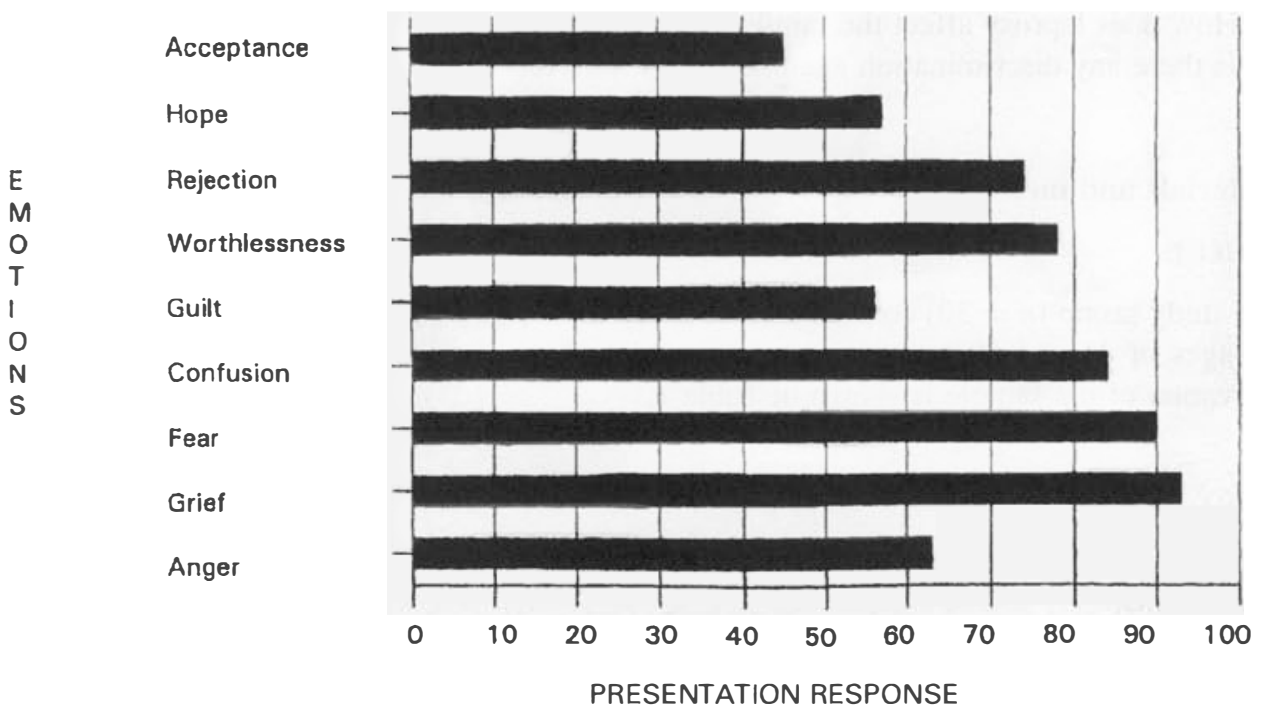

Figure 1. Nature and intensity of emotions directly after diagnosis as obtained by means of semi-structured interviews.

emotions that followed directly after the diagnosis of the illness. They had to grade the intensity of emotions, e.g. anger, grief or fear. The results are shown in Figure 1. Heartsore, fear and bewilderment were the most common emotions directly after diagnosis. Acceptance of the disease and hope for the future scored very low. Subjects blamed God, their ancestors, relations and family members for the disease. Many of the subjects did not know who had brought the disease to them. This could possibly explain the observation that only 10 subjects felt aggression towards the person that had given the disease to them. Intense grief was the most general reaction on hearing the diagnosis of leprosy. The grief originated from the following factors:

- Stigmatization because of certain passages in the Bible. Some leprosy sufferers were isolated because members of the community felt that such patients must be segregated according to biblical injunctions. In spite of these data, religion can offer an emotional crutch for many leprosy sufferers.

- A (sometimes justified) fear of rejection by family, friends and the community. A feeling of distinctiveness within the leprosy community and the resulting loneliness.

- The belief that leprosy is incurable.

- Fears of relatives and the community regarding the contagiousness of the disease. Twenty-six patients reported that people were afraid of physical contact with them.

All respondents worried while they were in hospital. Factors that caused the most worry were: financial matters (23), spouse and/or children while still married (30), subject's attendance at work (28) and possibility that subject might lose his/her job (30).

The majority of leprosy sufferers felt that lengthy institutionalization had more disadvantages than advantages. It is therefore not surprising that respondents rather wish to die. Eleven patients had contemplated suicide; six of these were male. 
TRADITIONAL HEALERS

In leiu of medical treatment, 11 subjects first consulted a sangoma before visiting a medical doctor/clinic. The reasons were as follows: belief that a spell had been cast on them, family influences (relatives had convinced the patient that they had been bewitched) and the influence of tradition (observations such as 'This is our doctor'). In some cases where medical doctors were unable to make a diagnosis, some patients turned to sangomas for advice.

\section{SATISFACTION WITH MEDICAL TREATMENT}

Only eight subjects stated that they did not believe the medical doctor who told him/her that they had leprosy. Some subjects were of the opinion that the doctors had not imparted the essential medical information to them. In certain cases, a definite fear for the disease among nursing personnel in general hospitals existed. These tendencies led to aggressiveness by some respondents. Generally speaking, the subjects were very satisfied with the treatment they received from the Leprosy Mission and at Westfort Hospital. This is reflected in the fact that 23 of the respondents, after being discharged, requested that a rehabilitation of ficer or a representative of the Mission should pay them a visit. Only two of 30 leprosy sufferers had been treated insensitively by rehabilitation of ficers in their own opinion.

\section{MARITAL RELATIONSHIPS}

Twenty-three members of the group studied were married at some stage. From this married group, nine men and seven women had been deserted by their marriage partners because of the leprosy. Contributory factors leading to this were an inability to provide security (psychological, social and economic) as well as problems concerning sex with his/her spouse. Of the 21 leprosy sufferers who were partners in a sexually active relationship, nine were less active after they contracted the disease. The following reasons were suggested for this decline:

- A decline in physical strength.

- Impotence.

- Uncertainty about the true feelings of the sexual partner. Some leprosy sufferers were hesitant to make a sexual approach, being under the impression that their spouses had a fear of contracting the disease and therefore did not wish to have sexual intercourse with their partners.

- Embarrassment by ulcers.

- Afraid of the possible transmission of the disease.

- Marriage partner fearful of contracting the disease.

FAMILY LIFE

In certain cases where leprosy sufferers were abandoned by their spouses, the family or their household served as an important source of support. Rejection appeared quite frequently, as 10 of the respondents' families had rejected them after diagnosis. Many of the subjects kept the name of their disease secret. When subjects did make it known, 20 were rejected by their friends. Fear of the transference of the disease is accepted as the largest single cause. 
WORK

All subjects were afraid of losing their work, and 17 did not mention the name of their disease to their employers. Doubt about the productivity of sufferers was the main reason why employers displayed a negative attitude towards the subjects. Patients also complained that the disease did indeed handicap them in their daily activities. Lack of mobility was a further handicap to participation in social activities in church, cinemas and dance halls.

\section{Discussion}

Leprosy can exercise a strong influence on the behaviour of a leprosy sufferer. Where the disease has been present since childhood, it can influence a patient's behaviour for the rest of life. The high rate of suicidal thoughts by leprosy sufferers (11 in this group) highlights the patient's concept of disease and their way of coping. The identification of the needs of leprosy patients has been presented. A variety of emotions are intensely experienced by leprosy sufferers. Grief appears to be the first and most general reaction. This implies that the leprosy sufferer must receive support as soon as possible. Also, doctors must supply factual information about the disease (and especially about the origin of deformities) to leprosy sufferers as soon as possible after diagnosis. The fear of this disease among some of the nursing staff in general hospitals emphasizes the importance of effective training in the medical aspects of leprosy. Leprosy sufferers in general are negative about lengthy institutionalization. Therefore, hospitalization can have a negative effect on his/her view of the disease. It is important that patients should have the freedom, as far as possible, to decide whether they want to be institutionalized or not.

In many instances, a rehabilitation of ficer gives a person the first indication that he/she is suffering from leprosy. The swift provision of essential information about the disease to the sufferer and their family and relatives is of utmost importance. At present, the absence of a training programme for field workers on the effective counselling of leprosy sufferers is a concern. The design of such a programme and effective training of field workers is very important.

Marriage and family ties are all influenced by leprosy. Even where communication between leprosy sufferers and their marriage partners is unrestricted, lack of information (with both partners) can cause wrong perceptions about the disease, which in turn have a detrimental influence on the marital relationship and could in some instances even lead to divorce. Rejection by family members is based on a wrong perception regarding the contagiousness of leprosy. If the family members accept the leprosy sufferer after diagnosis, the household members are an indispensable source of support. Churches should intensify their support for patients. Erroneous interpretation of the Bible gives rise to stigmatization, and therefore church teaching should rectify this.

The question can be raised, however, whether employers can be blamed for not employing or retaining the services of leprosy patients when jobs are scarce even for physically fit people. To find a solution, attention should focus on supporting bodies for leprosy sufferers. If leprosy sufferers could receive training while institutionalized, this might enhance their chances of employment.

In conclusion, the psychosocial needs of leprosy sufferers in South Africa are similar to those of leprosy sufferers in other parts of the world in three ways: 
- The need for self-acceptance. Respondents' views of life and the way in which they conceptualized the disease were decisive factors for their levels of mental health. The intensity of emotions experienced by leprosy sufferers immediately after diagnosis underscores how important it is to have support immediately available.

- The need for social acceptance. Of leprosy sufferers who had been married during the period of diagnosis, $40 \%$ of men and $30 \%$ of women were deserted by their spouses. Steyn et al.'s ${ }^{11}$ claim that security (psychological, social and economic) has become increasingly important for some South African black women was substantiated in this study, as male subjects gave this as the reason why their marriage partners had deserted them.

- The need for acceptance by the community. The extent to which the psychosocial needs of leprosy sufferers will be met depends in part on the way in which they are treated by their support systems. These systems include patients, families and relatives, employers, medical doctors and hospital staff. The information transmitted should be consistent.

The following recommendations can be made based on these findings:

- The design, implementation and evaluation of a training programme for leprosy field workers regarding the effective counselling of leprosy sufferers.

- The development of strategies to de-institutionalize leprosy sufferers and to integrate them into the community.

- The design, implementation and evaluation of a marriage enrichment programme for leprosy sufferers and their marriage partners.

\section{References}

1 The Leprosy Mission. Summary of field programme statistics. The Leprosy Mission, Johannesburg, 1992.

2 Kaufman A, Marian SSG, Nelville J. The social dimension of leprosy, 2nd edn. ILEP, London, 1986.

3 Thangaraj RH. A manual of leprosy, 6th edn. Printaid, New Delhi, 1989.

${ }^{4}$ Brayboy ME. The sociological effects on an individual with Hansen's disease. The Star, 1984; 14, 4-5.

5 Olivier HR. On being diagnosed a leper: a paradign of archetypal thinking. S Med J, 81, 1426-1432.

6 African Medical and Research Foundation. A guide to leprosy for field staff, 2nd edn. African Medical and Research Foundation, Nairobi, 1983.

7 Van Parijs LG. Health education in leprosy work. A manual for health workers, 2nd edn. Stanley L. Hunt, Northamptonshire, 1988.

8 World Health Organization. A guide to leprosy control, 2nd edn. WHO, Geneva, 1988.

9 Berreman, JM. Childhood leprosy and social response in South India. Soc Sci Med, 1984; 19, 853-865.

${ }_{10}$ Mishler EG. Social contents of health, illness and patient care. Cambridge University Press, Cambridge, 1981.

11 Steyn AF, Le Roux T, Van Wyk D. Die gesin: gister en vandag. Academica, Pretoria. 